\title{
Neighbourhood effects on youth educational achievement in the Netherlands: can effects be identified and do they vary by student background characteristics?
}

\author{
Brooke Sykes \\ Amsterdam Institute for Metropolitan and International Development Studies, University \\ of Amsterdam, Nieuwe Prinsengracht 130, 1018 VZ Amsterdam, The Netherlands; \\ e-mail: b.n.sykes@uva.nl
}

\section{Hans Kuyper}

Institute for Educational Research, University of Groningen, Grote Kruisstraat 2/1, 9712 Groningen, The Netherlands; e-mail: h.kuyper@rug.nl

Received 19 August 2008; in revised form 19 November 2008

\begin{abstract}
Adding to the growing body of research examining neighbourhood effects in European contexts, this study investigates the associations between the educational achievement of Dutch youth and their neighbourhood conditions. We further consider whether these associations vary by student socioeconomic status (SES), gender, or nativity. Results from a multilevel analysis of 17836 secondary school students living in 3085 neighbourhoods indicate significant relationships between several dimensions of the neighbourhood context and educational achievement. Student SES and nativity appear to moderate some of these effects. In particular, we find the negative effect of neighbourhood disadvantage to be almost entirely restricted to native youth. The achievement outcomes of students with higher levels of SES also appear to be less affected by neighbourhood affluence and disadvantage than those of lower-SES students. Our results suggest that the impact of neighbourhood conditions on certain groups of youth may be obscured in studies that measure average neighbourhood effects across all individuals. Future research which examines neighbourhood effects and mechanisms across subgroups of youth, and which examines the links between the neighbourhood, family, and school contexts, can help us to better determine the neighbourhood's role in youth education.
\end{abstract}

\section{Introduction}

How people are shaped by the environments they live in has been an important and recurrent question in the social sciences (Park and Burgess, 1924; Shaw and McKay, 1942; Wilson, 1987). Researchers from a range of disciplines have investigated whether individuals' social, cognitive, health, and behavioural outcomes are influenced by the places they live. Children and adolescents have been the focus of much of this research, with educational outcomes being one of the key areas of interest (Ainsworth, 2002; Leventhal and Brooks-Gunn, 2000; Oliver et al, 2007). Neighbourhoods are thought to be particularly relevant for young people, as many spend a vast amount of their time there-residing, socialising with friends, participating in local activities, and often attending local schools and day care centres. These children and youth will thus have numerous daily interactions with local peers, adults, and services; their behaviour, attitudes, and opportunities will be in part shaped in this setting (Bronfenbrenner, 1989; Brooks-Gunn et al, 1997).

The present study adds to the fields of neighbourhood and educational research by examining the existence and nature of neighbourhood effects on youth educational achievement in the Netherlands. In this paper we aim to assess the potential for the neighbourhood context to affect educational achievement in the Netherlands; to test whether certain neighbourhood conditions are associated with individual achievement; and to examine whether these associations vary across student socioeconomic status (SES), gender, or nativity. 
This paper makes several contributions. First, the Dutch context is an interesting setting in which to examine neighbourhood effects on education. In addition to a tradition of strong redistributive policies in the areas of housing and income, all schools (ie public and denominational/private) are funded nationally on an equal basis, with a weighted-funding scheme allocating extra funds to schools with higher shares of disadvantaged pupils. Parents are also free (and obliged) to choose their child's school, as there is no system of school catchment areas in the Netherlands. These factorsbroad welfare redistribution, open school choice, and compensatory funding to schools - are interesting considerations in a study of neighbourhood effects on education, as they potentially reduce the likelihood of individual educational outcomes being linked to place of residence. Second, the focus is on an age group and outcome, which have been found to be susceptible to neighbourhood influences in past North American (Ainsworth, 2002; Crane, 1991; Crowder and South, 2003; Leventhal and Brooks-Gunn, 2000) and European (Andersson, 2004; Kauppinen, 2007; McCulloch, 2006) studies, but which have received little attention in Dutch neighbourhood research. And, third, a nationally representative dataset is used, with individual, family, and educational information for around 18000 students, or $10 \%$ of all Dutch students who entered secondary school in the school year 1999/2000. The nesting structure of students within neighbourhoods allows us to use multilevel regression analysis, which is generally a more accurate estimation of neighbourhood effects than traditional regression (Raudenbush and Bryk, 2002; Snijders and Bosker, 1999). Multilevel analysis also provides a means for modeling crosslevel interactions, which enables us to test whether individual characteristics moderate the effects of neighbourhood conditions.

Section 2 briefly reviews the mechanisms thought to drive neighbourhood effects on children and youth. Findings from European studies of neighbourhood effects on educational outcomes are then summarised in section 3 , followed by a description of the current study's research methodology and design in sections 4 to 6 . Results from a series of multilevel regression analyses are then reported in section 7 , followed by a discussion of the findings and a conclusion in section 8 .

\section{How might the neighbourhood influence youth?}

Wilson (1987) brought the issue of neighbourhood effects to the forefront in the US when he argued that living in a poor neighbourhood could exacerbate the effects of individual poverty. He saw things such as the shared norms, the level of parental monitoring and supervision, and the availability and quality of role models in a neighbourhood as potential means by which individuals could be negatively affected by their disadvantaged residential surroundings. Since his work, theoretical models have expanded to include potential beneficial neighbourhood effects, such as those related to the presence of affluent neighbours, residential stability, or high levels of collective efficacy.

While the immediate family is known to be the most important context for young people's development and outcomes in general, it is increasingly acknowledged that individuals and families are situated in, and react to, broader neighbourhood and community structures and processes (Bronfenbrenner and Morris, 1998; Rankin and Quane, 2002; Sastry et al, 2006). The mechanisms connecting individuals' and families' behaviour and outcomes to their residential contexts have been linked to various school-level, peer-group-level, individual-level, and neighbourhood-level processes. These mechanisms include the level of institutional resources in the neighbourhood (eg the presence and quality of local schools, parks, libraries, health services), collective socialisation (eg adult monitoring and supervision, access to role models), peer relations 
(eg when language skills or attitudes towards schooling are affected by interaction with local peers), norms and collective efficacy (ie conditions of mutual trust, willingness to intervene for the common good, shared expectations among residents), and stigmatisation (eg negative stereotyping of neighbourhoods by external actors) (Galster et al, 2007; Jencks and Mayer, 1990; Sampson et al, 2002).

The role that parents and families can play in the transmission of neighbourhood effects to children and youth has also been highlighted (Kohen et al, 2008; Pinderhughes et al, 2001). Here, the notion is that, in addition to direct effects of the neighbourood environment, children can be affected indirectly through the neighbourhood's influence on parenting and family factors. In a longitudinal study of Canadian children, Kohen et al (2008) identified the effects of neighbourhood deprivation on family functioning and maternal emotional health, which, in turn, had consequences for children's outcomes. They explain that "neighborhood-level economic and social hardship operate in a similar fashion to family-level disadvantage in creating conditions that stress the family unit and ultimately impact children" (page 164).

\section{Youth education and neighbourhood effects: European evidence}

Several decades of neighbourhood effects research in the US has provided a good deal of evidence that neighbourhood conditions matter for a variety of individual outcomes (for reviews see Dietz, 2004; Leventhal and Brooks-Gunn, 2000; Sampson et al, 2002). Evidence of neighbourhood effects is thought to be particularly strong when educational outcomes are considered (Leventhal and Brooks-Gunn, 2000), with studies documenting area-based influences on outcomes such as educational attainment (Duncan, 1994), dropping out of school (Crane, 1991), and test scores (Ainsworth, 2002). Although the research field is younger in Europe, a small but growing base of European evidence also supports the notion that neighbourhood conditions may have independent effects on individual educational outcomes. As the US findings have been widely summarised and reviewed elsewhere (see above) and because of the setting of the current study, this section focuses on European research.

In Scotland, Garner and Raudenbush (1991) tested for the effects of neighborhood social deprivation on the educational attainment of 2500 youth. They found neighbourhood deprivation to have a significant negative association with individuals' overall attainment after controlling for a wide set of individual and family background characteristics. They identified the effect of neighbourhood deprivation as being small, but not inconsequential. For youth of otherwise identical background and prior-ability scores, the effect of neighbourhood deprivation could be enough to substantially improve their prospects in obtaining future employment.

Several studies from Sweden have also shown support for neighbourhood effects on educational outcomes. In a multilevel analysis of 2400 individuals in their midtwenties, Andersson (2004) found characteristics of individuals' neighbourhoods during adolescence to be associated with educational attainment and occupational status (and, to a lesser extent, income status) in early adulthood. She found both social (eg income, SES, household composition) and physical aspects (eg dwelling type, tenure) of neighbourhoods to be significantly related to individual outcomes. In a later study, Andersson and Subramanian (2006) found neighbourhood socioeconomic resources and instability to significantly predict school attainment in a sample of 200000 Swedish youth. The strongest effects came from what they refer to as 'sociocultural' characteristics of the neighbourhood-namely, the share of the population with a university degree, the share of blue-collar workers, and the average level of social assistance benefits. 
A recent study by Brännström (2008) echoed the finding that neighbourhood conditions are associated with school achievement in Sweden. He examined secondary school achievement for around 26000 youths, and found that while neighbourhood conditions are independently related to school outcomes this effect is attenuated by the school context. He found the neighbourhood-level variability in achievement to drastically reduce upon inclusion of the school context in the analysis - a finding that points to the role of schools as mediators of neighbourhood effects.

In Helsinki, Kauppinen (2007) used a sample of 10906 youth to test whether neighbourhood conditions had an impact on (a) whether students completed secondary school and (b) the type of secondary school diploma obtained (ie academically orientated versus vocational). He found effects on the (b) outcome only. The neighbourhood condition driving the effect was the 'concentration of affluence', a summary variable based on the share of high-income residents and residents with high educational and occupational status. Building on these research findings, Kauppinen (2008) further explored neighbourhood effects in Helsinki, incorporating youths' school contexts into the analysis. His findings were in agreement with those of Brännström (2008) and with theoretical discussions of neighbourhood effect mechanisms: the school context is one of the pathways through which neighbourhood conditions affect educational outcomes. While the school context attenuated much of the neighbourhood effect, Kauppinen found evidence of unique neighbourhood effects as well, driven by differences in neighbourhood SES. After controlling for a range of school and background characteristics, students from higher status areas were significantly more likely to pursue secondary school in the upper (academic) track than students in lower status areas.

In Britain, McCulloch and Joshi (2001) found mixed evidence for the effects of neighbourhood deprivation on young children's cognitive test scores. They tested for effects separately on three age groups, corresponding to three different developmental phases. Associations between neighbourhood poverty and cognitive outcomes could be identified for children aged 4-5 years, to a limited extent on the 10-18-year-old group, but not on the 6-9-year-olds. They also tested for links between neighbourhood deprivation and children's behaviour problems, but did not find any significant associations. Using the same data sources, McCulloch (2006) again tested for associations between children's outcomes and their neighbourhoods, applying a different method of measuring neighbourhood characteristics. While McCulloch and Joshi (2001) used an 'index of deprivation' based on four aspects of neighbourhood composition, McCulloch (2006) used a set of thirty-seven neighbourhood characteristics to create a classification of ten neighbourhood types. He found certain neighbourhood types to significantly predict children's cognitive and behaviour outcomes. For instance, children in neighbourhoods described as 'deprived city areas' had lower cognitive test scores and higher levels of behaviour problems than average, while children living in areas classified as 'prosperous areas' had significantly better cognitive test scores than average. McCulloch (2006) explains that the variations in his findings and that of McCulloch and Joshi (2001) are likely the result of the greater informativeness of the neighbourhood classification he used, compared with the one-dimensional deprivation index used earlier.

Several analyses in a variety of European settings have found significant associations between neighbourhood characteristics and educational outcomes. While the effects found, both in Europe and elsewhere, are generally small, particularly in comparison with effects from family background characteristics, a frequent claim is that they are not trivial. Living in certain environments appears to be able to significantly improve young people's chances of graduating with higher credentials in secondary school, staying in school longer, and achieving better grades - factors that are known to have implications for later success in higher education and the labour market. 


\section{The present study}

\subsection{Research questions}

In line with the aims of this study, the following research questions were formulated:

(1) How much of the variation in young people's educational achievement exists between neighbourhoods?

(2) Are youths' neighbourhood conditions associated with their school achievement, after taking individual background characteristics into account? If so, what neighbourhood conditions contribute to these associations?

(3) Do the associations between neighbourhood conditions and educational achievement differ by student SES, gender, or nativity?

\subsection{Research context}

Children in the Netherlands enter secondary school around the age of 12. Dutch secondary education is a highly differentiated system, consisting of several different tracks of education, distinguished primarily by the learning ability and trajectory of students. There are five main tracks: $\mathrm{A}=$ preuniversity education (6 years); $\mathrm{B}=$ senior general secondary education (5 years); $\mathrm{C}=$ junior general secondary education (4 years); $\mathrm{D}=$ prevocational education (4 years); $\mathrm{E}=$ prevocational education with individualised support (4 years). Students are advised by their primary schools as to the most suitable track, based on results of a standardised test taken in the final year of primary school, as well as the student's motivation, interests, and general performance. While some secondary schools offer only one track, the majority are combined schools offering several different tracks and many offer all five tracks. As mentioned above, parents have the freedom to choose their child's school - both at the primary level, and, within the limits of their child's (advised) learning trajectory, at the secondary level.

The tradition of redistributive policies in the Netherlands extends to the realm of education. In primary education, all students are assigned a weight based on their socioeconomic and ethnic background, and the total of these weights determines the level of additional funding given to the school. At the level of secondary education, schools are allocated extra funding through a 'Local Compensatory Policy' administered by the municipality, and schools with large shares of ethnic minority pupils also receive targeted funds. Education is government financed and free of charge, with public and private schools funded on an equal footing by the national administration. In principle, all children and youth have equal access to education, regardless of family economic resources, place of residence, or other factors. In reality, practices related to how parents choose schools and how schools admit students are likely to have some effect on the evenness in access (see Gramberg, 1998; Karsten et al, 2003; 2006; Teelken, 1999; ten Broeke et al, 2004).

\section{Data and methods}

\subsection{Data sources and sample characteristics}

The data analysed in this paper come from two sources. All individual data are derived from a large-scale, longitudinal cohort study of secondary school education in the Netherlands, the Voortgezet Onderwijs Cohort Leerlingen (VOCL'99). Beginning in 1999, this study follows a cohort of students from their first year of secondary school (average age 13 years, equivalent to US grade 7) until they leave full-time education. All students who entered the first year of a sample of 126 schools belong to the cohort, totaling 19391 students. Statistics Netherlands constructed the sample, recruited the schools, and is responsible for (ongoing) data collection. The sample has been found 
to be representative of schools and students in Dutch secondary education (van Berkel, 1999).

The results reported below are from analyses of just under 18000 students. The original sample size was reduced based on the following criteria: (a) no missing values on the dependent variable (educational achievement); (b) no missing or erroneous home postcodes (used to identify students' neighbourhoods); and (c) students' neighbourhoods were not missing essential data. After these reductions were made, 140 students (less than $1 \%$ of the sample) were further excluded because their ethnic background could not be identified. These four criteria reduced the initial sample size by 1555 students $(8 \%)$.

All neighbourhood-level data come from Statistics Netherlands. While the VOCL'99 was designed to be representative of students and schools in the Netherlands, additional analyses were required to determine the representativeness of the neighbourhoods appearing in the dataset. We found the neighbourhoods in our sample to be very representative of those in the Netherlands in terms of socioeconomic characteristics (ie average income, share of high-income and low-income residents, share of unemployment benefit recipients) and ethnic minority composition, with all values of Cohen's effect size $d$ lower than what is considered a 'small' effect (range of $d=0.05-0.14$ ) (Cohen, 1988). These neighbourhoods are, however, somewhat more urban in character, with higher levels of population and address density $(d=0.60$ and 0.65$)$ and slightly lower shares of homeownership $(d=0.35)$.

\subsection{Individual-level predictors}

Students' background characteristics came from a parent questionnaire and school administrative data in the VOCL'99, and include: age, gender, nativity $[0=$ Dutch, $1=$ nonnative (a student was considered to have a nonnative background if he or she or at least one parent was born abroad], family SES (based on the highest level of parental educational attainment, from $1=$ primary school or less to $5=$ university or postgraduate degree), and family structure $(1=$ married, $2=$ registered partnership or living together, $3=$ divorced, widowed, not married, $4=$ unknown $/ \mathrm{missing}$ ). Rather than exclude the 1880 cases for which no parental education information was available, regression imputation with a random (stochastic) component was used to impute missing values, based on the relationship between relevant variables with complete cases. All other individual data were complete.

The outcome variable of interest is students' educational achievement, operationalised as the score on a standardised test taken in the first year of secondary school, during February and March 2000. The test was developed by the Dutch Institute for Educational Testing (CITO Groep) and consisted of three components: Dutch language, arithmetic, and information processing. Each component was scored out of 20, with 60 being the highest possible test score; the mean score of our sample was 36.5 (standard deviation $=10.8$, range $=5-60$ ). The test was found to be a highly reliable measure of achievement, with a Cronbach's alpha of 0.90 (Kuyper et al, 2003). We examined the scores of each test component for an indication of whether ethnic minority students might be disadvantaged by the language section (however, our sample includes only students enrolled in 'regular' secondary education; newcomers to the Netherlands with language barriers and other special needs are enrolled in transition classes). As expected, native Dutch students scored higher, on average, on all three test components; however, this was the least so for the language component (mean scores for language, arithmetic, and information processing for Dutch followed by nonnative students are, respectively, 12.7 versus 11.7, 12.5 versus 11.2, and 12.1 versus 10.5) (Kuyper et al, 2003). 
Table 1. Mean test achievement by class type.

\begin{tabular}{lrrr}
\hline Class type & $n$ & Mean & Standard deviation \\
\hline A & 1369 & 49.2 & 5.8 \\
AB & 4992 & 44.5 & 6.7 \\
B & 516 & 40.7 & 6.8 \\
ABC & 1114 & 39.6 & 8.1 \\
BC & 2760 & 36.2 & 6.9 \\
C & 2175 & 32.1 & 7.9 \\
CD & 1970 & 28.9 & 7.5 \\
D & 1694 & 26.5 & 7.1 \\
DE & 541 & 21.9 & 7.1 \\
E & 705 & 19.1 & 6.1 \\
Total & 17836 & 36.5 & 10.8 \\
Note. A preuniversity, B= senior general secondary, C = junior general secondary, \\
D=prevocational E= prevocational with individualised support. \\
\end{tabular}

Table 1 shows the mean achievement scores for students in our sample, differentiated by educational class type in year 1 (some of the class types in year 1 consist of one track, while others are combination types, consisting of two or three adjacent tracks). The pattern of achievement in relation to education type is clear in the tablethose in higher tracks perform significantly better. The average difference between adjacent class types is 3.3 points on the test, or 0.31 standard deviations. The differences in this table will be useful when estimating the magnitude of effects in later analyses.

\subsection{Neighbourhood-level variables}

Students' home postcodes, recorded in the first year of secondary school, were used to identify their neighbourhoods. The neighbourhood unit used is the 'buurt' - an administrative spatial subunit representing the lowest neighbourhood level in the Netherlands. In 1999, there were 10737 of these neighbourhood units in the Netherlands, with a mean population of 1468 . These neighbourhoods vary in terms of population size and surface area, but tend to be defined on the basis of natural borders, such as roads, railways and waterways, and parks, and by building styles and periods. The students in the VOCL sample resided in 3085 of these neighbourhoods in 1999, representing around $29 \%$ of all neighbourhoods in the Netherlands.

A range of data was available for these neighbourhoods through Statistics Netherlands. Guided by theory and literature, the following selection of neighbourhood variables was made: share of high-income residents, low-income residents, unemployment benefit recipients, mean income per income earner and per resident, housing tenure (share of homeownership), mean home value, share of immigrants with a non-Western background, and neighbourhood urbanicity. In order to summarise these variables into a smaller number of constructs and to eliminate the problem of multicollinearity, a principal components analysis (PCA) was performed. We excluded the measure of non-Western immigrants from the PCA because of its highly nonnormal (positively skewed) distribution and because of the interpretability of neighbourhood dimensions. For this measure, a series of dummy variables was used to represent five categories of neighbourhood ethnic minority concentration, ranging from $(1=0 \%-1 \%)$ to $(5=>20 \%)$. 'Urbanicity' was also left out of the PCA because it is a categorical predictor. This predictor was constructed by Statistics Netherlands and is based on the average density of addresses in a neighbourhood, 
ranging from 'very low density' $(1=<500$ addresses per $\mathrm{km})$ to 'very high density' $(5=>2500$ addresses per $\mathrm{km})$. We use this predictor as a control, to take differences between more or less urbananised neighbourhoods into account. To say something about the wider context within which the neighbourhoods are situated, we created a set of dummy variables based on the population of the surrounding municipality, from 'small city/rural' $(1=<50000)$ to 'large city' $(3=>150000)$.

The PCA revealed three underlying dimensions among the variables, hereafter referred to as neighbourhood affluence, neighbourhood socioeconomic disadvantage, and housing milieu. The three factors accounted for $89 \%$ of the total variance. Factor scores were calculated for each neighbourhood on these three dimensions and used in subsequent analyses. Based on congruent results from an orthogonal and oblique rotation, we used the orthogonal (varimax) factors, which are uncorrelated. To ensure the robustness of the factors, we replicated the PCA with all neighbourhoods in the Netherlands and derived analogous results.

The first factor, neighbourhood affluence, had high $(>0.6)$ loadings on the mean income per resident and per income earner, and the share of high-income residents. The highest loading on neighbourhood socioeconomic disadvantage was the share of unemployment benefit recipients, followed by the share of low-income residents. The share of homeownership and the mean home value loaded highest on the third dimension, housing milieu. Neighbourhood affluence gives an indication of the level of financial earnings in a neighbourhood, while neighbourhood socioeconomic disadvantage gives an indication of the extent of unemployment and low-income residents. These factors serve as proxies for the various processes and dynamics happening in the neighbourhood that are thought to explain why neighbourhoods are relevant for youth outcomes. These include the mechanisms previously mentioned: the kinds of role models and peer groups present, the shared attitudes, norms, and expectations (eg towards work and education), processes of stigmatisation, social control, and so on. The housing factor can be interpreted as an indicator of the physical housing environment (ie the value, tenure, and, to some degree, the quality of the housing stock), and also, indirectly, of the social milieu. The role of homeownership has been investigated for the potential benefits it provides residents and areas - for reasons such as the lower residential turnover, which results in a more stable neighbourhood environment, as well as the attitudes and behaviours that might be associated with having a financial stake in an area (Aaronson, 2000; Rohe and Steward, 1996). Homeownership has also been used as an indicator of neighbourhood stability, a factor which has been found to be predictive of the level of neighbourhood collective efficacy and social cohesion (Drukker at al, 2003; Sampson et al, 1999).

\section{Analysis}

Multilevel regression analysis was used to examine the relationships between educational achievement and individual, family, and neighbourhood characteristics. A two-level model was specified, with students (level-1 units) nested within neighbourhoods (level-2 units). We began our analysis by running a null or 'unconditional' model. This model is estimated to determine the amount of variance in the dependent variable attributed to the individual and neighbourhood level, and to determine the initial model fit for assessing later models. The variance values from this model are used to calculate the 'intraclass correlation coefficient' (ICC), a measure of the proportion of the total variance that is accounted for by (observed and unobserved) factors operating at each of the two levels. After running the unconditional model, we added individual and family characteristics. We then added neighbourhood characteristics, to address the main research question about the influence of neighbourhood conditions on youth 
educational outcomes. In the next model, we tested cross-level interactions, to address the research question concerning differential neighbourhood effects.

To test whether the addition of new parameters improves the fit of the model, the reduction in the $-2 \times \log$ likelihood (the 'deviance') was assessed. This quantity follows (asymptotically) the chi-squared distribution, with the degrees of freedom being equal to the difference in the number of parameters for the models being compared. The regression parameters in our model have the same interpretation as unstandardised regression coefficients in multiple regression-that is, they reflect the average change in the outcome variable associated with a one-unit increase in that parameter. To assess whether a specific regression coefficient is significant, it is divided by its standard error, which gives the (Student's) $t$-test statistic; a coefficient is significant at the 0.05 level when it is approximately twice the size of its standard error. All continuous predictors in the analysis were centred around their grand mean and a set of dummy variables was constructed for each categorical variable, with the modal category set as the reference category. This centring facilitates interpretation of the results and permits the modeling of cross-level interactions without the problem of multicollinearity (see, for instance, Snijders and Bosker, 1999). Because of this centring, the intercept of all models represents the mean score for an 'average' student (ie one with mean values on all predictors). All models were estimated using MLwiN 2.0 (Rasbash et al, 2000).

\section{Results}

\subsection{Descriptive results}

Table 2 displays the descriptive statistics for the individual-level and neighbourhood-level variables used in the analysis, including the mean or proportion, standard deviation, and range for each variable. The average age of youth in the sample is just over 13 years, the sample is split equally by gender, almost one fifth of the students have a non-native Dutch background, and the vast majority have parents who are married. The parental SES category with the highest frequency is 'secondary school education' in the higher stream, with $42 \% ; 11 \%$ of students have parents with a primary school education or less, and $10 \%$ have at least one parent with a university or postgraduate degree. The neighbourhood descriptive statistics were computed at the level of the neighbourhood $(n=3085)$. The first three variables are the measures derived from the PCA and those following indicate the share of ethnic minorities, urbanicity, and wider setting.

\subsection{Multilevel results}

Table 3 displays the results from a series of four increasingly complex models estimating youths' educational achievement. From the null model (model 1), the total variance is decomposed into the individual and neighbourhood level by calculating the ICC. In this study, nearly $28 \%-100[33.28 /(87.20+33.28)]=27.6)$ - of the unconditional variation in educational achievement is between neighbourhoods. This is considered a large ICC and indicates that, while there are clearly differences in educational achievement at the level of the individual, there are also substantial differences in achievement between neighbourhoods.

In model 2, the individual-level (level-1) predictors (age, gender, nativity, SES, family status) were added. The intercept of this model represents the mean score for a Dutch male student, with married parents, and an average age and SES. Age has a strong negative effect on achievement, with every additional year being associated with 4.94 fewer points on the achievement test. This effect reflects the fact that older students in the sample would mainly be those who were held back in school as a result of poor performance or learning difficulties, while the very youngest would be those who were put ahead because of exceptional abilities. The coefficient for gender provides no evidence that boys and girls differ consistently in their achievement scores. 
Table 2. Descriptive statistics: individual and neighbourhood variables.

Mean/ SD Minimum Maximum
proportion

\section{Individual-level variables $(n=17836$ students $)$}

Outcome variable

Educational achievement

Predictor variables

$\begin{array}{lr}\text { Age } & 13.03 \\ \text { Gender }(1=\text { girl, } 0=\text { boy) } & 0.50 \\ \text { Nativity }(1=\text { nonactive, } 0=\text { Dutch) } & 0.19 \\ \text { Family socioeconomic status } & \\ \text { primary school or less } & 0.11 \\ \text { secondary education, lower stream } & 0.16 \\ \text { secondary education, higher stream (reference) } & 0.42 \\ \text { higher professional education } & 0.21 \\ \quad \text { university or postgraduate } & 0.10 \\ \text { Family structure } & \\ \text { married (reference) } & 0.76 \\ \text { registered partnership or cohabitation } & 0.03 \\ \text { divorced, widowed, never married } & 0.09 \\ \text { missing } & 0.11\end{array}$

$\begin{array}{rccc}36.47 & 10.85 & 5 & 60 \\ 13.03 & 0.50 & 10.12 & 16.45 \\ 0.50 & 0.50 & 0 & 1 \\ 0.19 & 0.39 & 0 & 1 \\ & & & \\ 0.11 & & 0 & 1 \\ 0.16 & & 0 & 1 \\ 0.42 & & 0 & 1 \\ 0.21 & & 0 & 1 \\ 0.10 & & 0 & 1 \\ & & & \\ 0.76 & & 0 & 1 \\ 0.03 & & 0 & 1 \\ 0.09 & & 0 & 1 \\ 0.11 & & 0 & 1\end{array}$

Neighbourhood-level variables ( $\boldsymbol{n}=\mathbf{3} 085$ neighbourhoods)

Predictor variables

Neighbourhood affluence

$\begin{array}{lll}0.84 & -2.91 & 4.30 \\ 0.92 & -2.64 & 5.79 \\ 0.86 & -2.90 & 3.65\end{array}$

Housing milieu

Ethnic minorities (\% non-Western background)

$\begin{array}{ll}0 \%-1 \% & 0.22 \\ 2 \%-5 \% \text { (reference) } & 0.43 \\ 6 \%-10 \% & 0.16 \\ 11 \%-20 \% & 0.10 \\ >20 \% & 0.08 \\ \text { Neighbourhood urbanicity } & \\ \text { not urbanised (reference) } & 0.24 \\ \text { weakly urbanised } & 0.20 \\ \text { urbanised } & 0.21 \\ \text { strongly urbanised } & 0.22 \\ \text { very strongly urbanised } & 0.14 \\ \text { Wider setting } & \\ \text { small city/rural }(<50000) \text { (reference) } & 0.59 \\ \text { medium city }(50000-150000) & 0.28 \\ \text { large city }(>150000) & 0.13\end{array}$

Students with native Dutch backgrounds perform better, on average, than their peers with nonnative backgrounds. Family SES has a significant and strong positive effect on achievement - the average difference associated with a move from the lowest to highest SES level is approximately 9 marks on the test ( 0.84 standard deviations). The coefficients for family structure indicate that compared with having married parents, having parents in an unmarried cohabitation or having an unknown or missing family status is associated with lower test scores. This model reduces the individual-level (withinneighbourhood) variance by $20 \%$ and the between-neighbourhood variance by $44 \%$. The significant unexplained variance remaining in the model indicates that, even after controlling for students' background characteristics, significant differences in educational achievement exist between neighbourhoods. 
Table 3. Multilevel model of neighbourhood and individual-level effects on educational achievement.

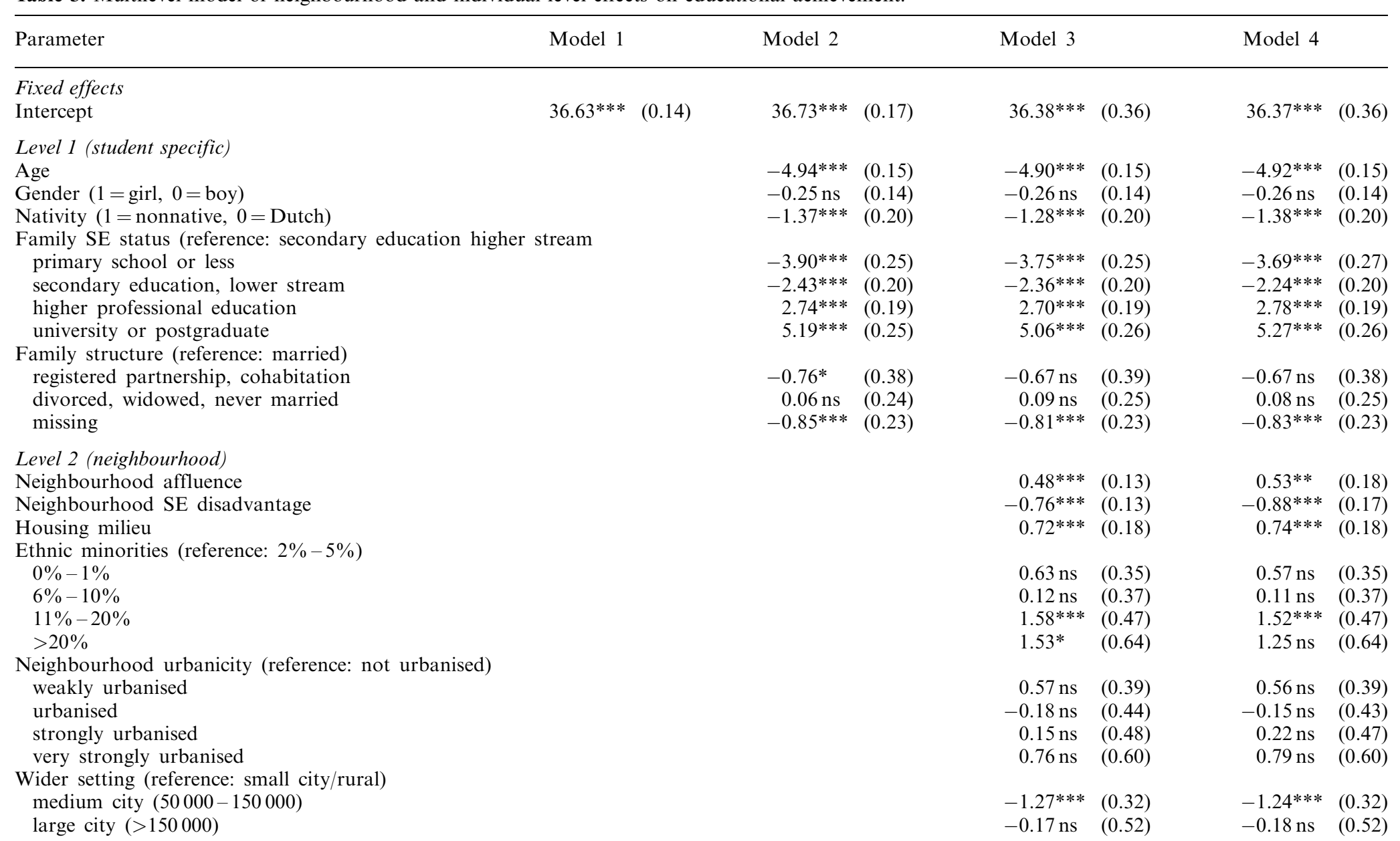




\begin{tabular}{|c|c|c|c|c|c|}
\hline Parameter & Model 1 & Model 2 & Model 3 & \multicolumn{2}{|l|}{ Model 4} \\
\hline \multicolumn{6}{|c|}{ Cross-level interaction effects } \\
\hline \multicolumn{4}{|c|}{ Neighbourhood SE disadvantage $\times$ nativity } & $0.75 * * *$ & $(0.20)$ \\
\hline \multicolumn{4}{|c|}{ Neighbourhood SE disadvantage $\times$ primary school } & $-0.21 \mathrm{~ns}$ & $(0.25)$ \\
\hline \multicolumn{4}{|c|}{$\begin{array}{l}\text { Neighbourhood SE disadvantage } \times \text { secondary education, } \\
\text { lower stream }\end{array}$} & $-0.57 * *$ & $(0.22)$ \\
\hline \multicolumn{4}{|c|}{$\begin{array}{l}\text { Neighbourhood SE disadvantage } \times \text { higher professional } \\
\text { education }\end{array}$} & $0.19 \mathrm{~ns}$ & $(0.22)$ \\
\hline \multicolumn{4}{|c|}{ Neighbourhood SE disadvantage $\times$ university, postgraduate } & $1.04 * * *$ & $(0.32)$ \\
\hline \multicolumn{4}{|c|}{ Neighbourhood affluence $\times$ primary school } & $0.43 \mathrm{~ns}$ & $(0.38)$ \\
\hline \multicolumn{4}{|c|}{ Neighbourhood affluence $\times$ secondary education, lower stream } & $0.34 \mathrm{~ns}$ & $(0.29)$ \\
\hline \multicolumn{4}{|c|}{ Neighbourhood affluence $\times$ higher professional education } & $-0.46^{* *}$ & $(0.22)$ \\
\hline \multicolumn{4}{|c|}{ Neighbourhood affluence $\times$ university, postgraduate } & $-0.17 \mathrm{~ns}$ & $(0.26)$ \\
\hline \multicolumn{6}{|l|}{ Random parameters } \\
\hline Within-neighbourhood variance & $87.20 * * * \quad(1.00)$ & $78.04 * * * \quad(0.89)$ & $78.16^{* * *} \quad(0.90)$ & $78.02 * * *$ & $(0.89)$ \\
\hline Between-neighbourhood variance & $33.28 * * * \quad(1.50)$ & $18.76 * * * \quad(0.99)$ & $17.02 * * * \quad(0.93)$ & $16.80 * * *$ & $(0.92)$ \\
\hline $2 \times \log$ likelihood & 133133.50 & 130461.40 & 130357.30 & 130311 & 1.90 \\
\hline
\end{tabular}

ns $=$ not significant; $* p<0.05, * * p<0.01$, and $* * * p<0.001$

Note. Standard errors are in parentheses. All continuous predictors are centred around their grand mean. SE= socioeconomic. 
In model 3, all neighbourhood-level predictors were added. These predictors led to a significant improvement in the model fit and explain a further $5 \%$ of the betweenneighbourhood variance in achievement. The predictors for neighbourhood affluence, socioeconomic disadvantage, and housing milieu all have significant associations with achievement. The strongest effect of these three predictors is from neighbourhood socioeconomic disadvantage. After adjusting for individual background characteristics and other neighbourhood conditions, a one-unit increase in the level of neighbourhood socioeconomic disadvantage is associated with a decrease in achievement of 0.76 marks, or 0.06 standard deviations. Neighbourhood affluence and housing milieu are positively associated with achievement.

Neighbourhoods with the greatest shares of residents with non-Western immigrant backgrounds (ie $11 \%-20 \%$ and $>20 \%$ ) have significant and positive associations with achievement, relative to the reference category $(2 \%-5 \%)$. However, reduced models (not shown) reveal that these positive effects are apparent only if differences in neighbourhood socioeconomic and housing conditions have been controlled for. In a reduced model with all individual-level predictors and only the neighbourhood ethnic minority predictors, living in the least ethnically concentrated areas is associated with a positive effect on achievement. Once neighbourhood socioeconomic and housing predictors are taken into account, this positive effect is no longer significant, implying that the effect can be explained by the more advantageous socioeconomic and housing conditions in these areas. The neighbourhood urbanicity predictors (model 3) are not significant, but the control for the wider context suggests that living in a neighbourhood located in a medium-sized city is associated with lower achievement, relative to living in a small city/rural area.

A series of cross-level interaction terms were introduced in model 4 to test for differential neighbourhood effects across student SES, gender, and nativity. Significant terms were retained in the model (see model 4, cross-level interaction effects). None of the significant effects included gender, implying that the neighbourhood effects tested here do not differ for boys and girls. The significant interaction between nativity and neighbourhood socioeconomic disadvantage (coefficient 0.75 ) suggests that the effect of neighbourhood disadvantage on achievement is much more relevant for native Dutch students. Nearly all of the effect of neighbourhood disadvantage in the model is a result of its negative impact on native students' achievement. Figure 1 illustrates this interaction by showing the predicted achievement for both groups of students, as a function of neighbourhood disadvantage. We also explored an interaction between student nativity and the share of ethnic minorities in the neighbourhood.

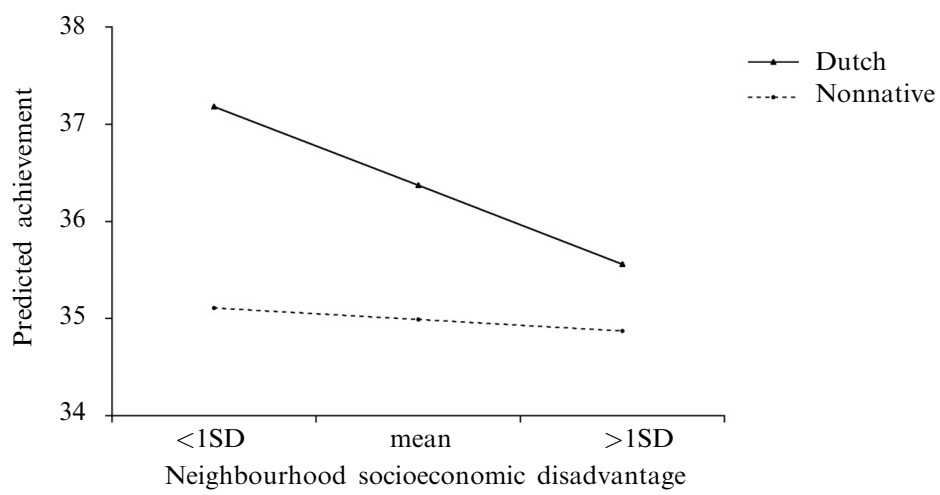

Figure 1. Predicted achievement as a function of students' background (Dutch/nonnative) and neighbourhood socioeconomic disadvantage. 
This produced one significant term, which was the interaction between nativity and the first $(0 \%-1 \%)$ category of ethnic concentration; however, because of low cell numbers (ie very few nonnative youth live in the neighbourhoods with $0 \%-1 \%$ minorities) and a lack of improvement in the model fit $(=7,4$ degrees of freedom, $p=0.14)$, this interaction was left out.

Cross-level interactions between student-level SES and neighbourhood disadvantage and neighbourhood affluence are also significant. While only one of the coefficients for the latter interaction reaches statistical significance, the inclusion of this interaction significantly improves the model fit $(=10,4$ degrees of freedom, $p<0.04)$ and reveals a coherent pattern. These two interaction effects indicate that the achievement of higher-SES students is less affected by neighbourhood socioeconomic conditions than that of lower-SES students. In fact, the outcomes of students with the highest level of SES appear to be virtually exempt from any real effects of these neighbourhood conditions. The interaction between student-level SES and neighbourhood socioeconomic disadvantage is shown in figure 2. The five levels of SES represent the lowest to highest levels of family SES in our sample.

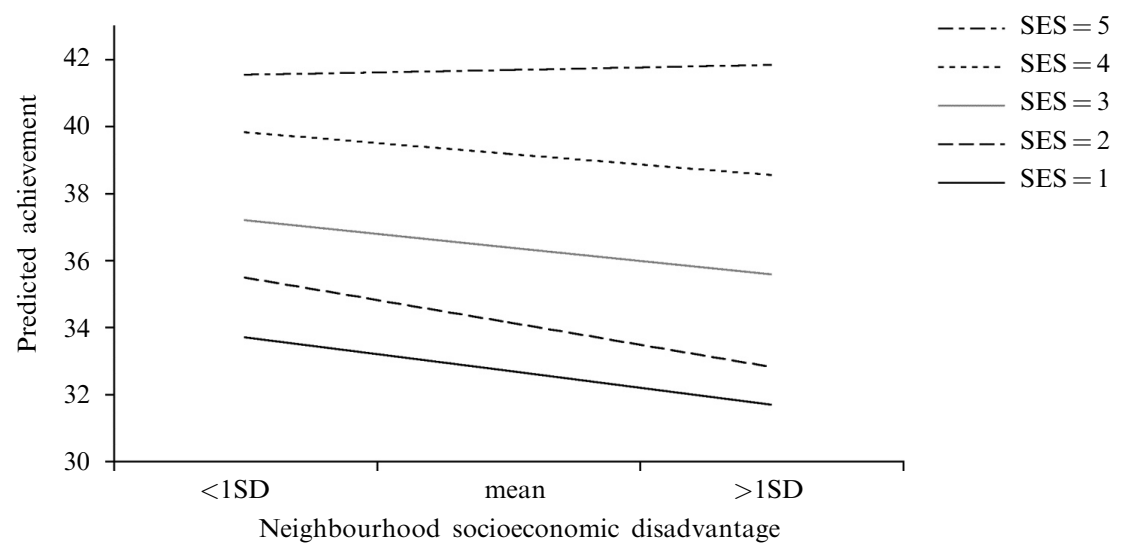

Figure 2. Predicted achievement as a function of student socioeconomic status (SES) and neighbourhood socioeconomic disadvantage.

By allowing individual characteristics to moderate the impact of neighbourhood conditions, we get a more accurate idea of the magnitude of neighbourhood effects for certain subgroups. The largest neighbourhood influence in our analysis is the negative impact of neighbourhood disadvantage on the achievement of lower-SES Dutch students. For these students, the difference in achievement associated with differences in neighbourhood disadvantage could be as much as 3.3 marks on the achievement test or 0.28 standard deviations (the effect associated with a 10th to 90th percentile change in the level of neighbourhood disadvantage). A difference in achievement of this size is greater than the achievement difference between some of the class types (refer to figure 1), more than the difference associated with a one level change in family SES, and more than double the disadvantage associated with having a nonnative background. An effect of this size is meaningful, especially when considering the differences between the class types and levels of SES. In our final model, the original withinneighbourhood variance has been reduced by $21 \%$ and the between-neighbourhood variance has been reduced by $50 \%$. The unexplained variance remaining in the final model is significant, indicating that the model can be improved and achievement can be further explained by the inclusion of additional variables. 


\section{Discussion and conclusion}

This paper set out to investigate the presence and nature of neighbourhood effects on the educational outcomes of youth in the Netherlands. This was achieved by first examining the clustering of achievement at the neighbourhood level, then testing for associations between individuals' neighbourhood conditions and their educational achievement, and, finally, examining whether these associations vary across certain student-level characteristics. The ICC showed that achievement is clearly clustered at the neighbourood level, with $28 \%$ of its variance associated with differences between neighbourhoods. This reveals a relatively large potential for factors associated with the neighbourhood to affect youth achievement. While much of this clustering could be explained by differences across neighbourhoods on the individual-level predictors (ie composition effects), we also found support for independent neighbourhood effects.

The results of the three neighbourhood indices support conventional ideas about neighbourhood quality: disadvantaged areas are associated with lower outcomes, and affluent areas and areas with stronger housing milieus (ie higher levels of homeownership and home values) are associated with better outcomes. Of these three neighbourhood measures, neighbourhood socioeconomic disadvantage had the strongest association with achievement. The share of residents receiving unemployment benefits and the share of low-income residents were the characteristics that loaded highest on, and essentially make up, this dimension. Although mediating processes have not been examined in this study, conditions of unemployment and low income could be tied to mechanisms such as collective socialisation, social networks, and limited opportunity structures. For example, high levels of unemployment could mean a lack of structuring norms and work ethnics modeled by adults with steady jobs (Wilson, 1987). They could also contribute to the perception of poor chances for future employment and the development of deviant attitudes towards regular employment or educational attainment. Disadvantaged neighbourhoods might also lack some of the social control mechanisms concerning education which have been reported to exist in better-off areas, such as collective expectations of performing well and going on to higher education, or the sanctioning of behaviour such as dropping out (Gramberg, 2000).

Evidence of differential neighbourhood effects by student SES and nativity were found. The negative association between neighbourhood socioeconomic disadvantage and student achievement was almost entirely restricted to native Dutch students. This implies that the levels of neighbourhood unemployment and low income, while relevant for the educational outcomes of native students, do not bear much weight for the outcomes of nonnative youth. In a German study examining neighbourhood effects on youth delinquency, Oberwittler (2007) also found nonnatives to be less susceptible to the effects of neighbourhood disadvantage. He suggests that although native and immigrant youth may live in the same neighbourhoods their social experiences and 'lifeworlds' may differ to some degree. In support of this, he found the way youth perceive neighbourood social problems to differ significantly by nativity. A relevant factor may also be the school conditions of nonnative students in disadvantaged areas. In the Netherlands, schools with higher shares of ethnic minority and low-SES students receive extra funding for things such as extra teachers and smaller class sizes; these schools can also develop practices geared towards the particular needs of their intakes. As most ethnic minority students living in disadvantaged areas would attend schools with extra support, it is possible that these schools are able to compensate for the negative effects on achievement associated with such areas.

The achievement outcomes of higher-SES students were also found to be less affected by neighbourhood socioeconomic conditions than the outcomes of lowerSES students. It appears that lower-SES students make greater achievement gains, 
on average, from living in affluent neighbourhoods, and incur greater losses from living in disadvantaged areas, than do higher-SES students. This interaction effect might be partly explained by the role of parents as moderators of context effects. For example, higher-SES parents might be better able to divert negative neighbourhood effects or to replace what is missing in their immediate surroundings by sending their children to better schools further away, or providing them with extra learning support or activities (Ellen and Turner, 1997). The degree to which high-SES and low-SES students and families are orientated towards their neighbourhoods might also be relevant. For example, if higher-SES families have less locally based social networks, or are able to send their children to schools or extracurricular activities that might be at a distance, it could be the case that they are less likely to be affected by their local residential conditions. These interaction effects suggest that it is the achievement outcomes of low-income Dutch students which are the most susceptible to a neighbourood effect.

In accordance with most of the European findings in this field, the estimated neighbourhood effects found in our analysis were of a modest magnitude. Small differences in neighbourood conditions are not associated with sizable consequences for achievement; however, larger differences, especially for certain subgroups, are associated with meaningful impacts. The importance of (even small) neighbourhood effects and the relevancy of such effects for policy are topics that have been widely discussed (see Dorling et al, 2001; Lupton, 2003). Oliver et al (2007, page 865) point out that the practical importance of small neighbourhood effects "may be far greater than their apparent empirical magnitude, partly as a result of the uncertainty about the independence of individual and neighbourhood factors". Jackson and Mare (2007) also note that although neighbourhood effects may be small, in some cases, conditions associated with the neighbourhood may be more easily changed than certain family (and genetic) factors. The widespread prevalence of disadvantaged neighbourhoods may also mean that the overall impact of these areas on youth education is large.

This paper has a number of limitations and ideas for future research. Although our study has several strengths - including the large and nationally representative dataset, the high reliability of the outcome measure, and the test for differential neighbourhood effects - it does not address several of the important obstacles in identifying and measuring (causal) neighbourhood effects. These challenges have been well documented (see Dietz, 2002; Galster, 2008; Sastry et al, 2006) and apply to this study. Most importantly, this includes the issue of endogeneity, specifically that related to 'selection bias' - the fact that people are not sorted randomly into neighbourhoods. Because individual factors, such as personal preferences, help to sort people into neighbourhoods, neighbourhood selection, and therefore neighbourhood conditions, should be treated as endogenous. In our case, we cannot be sure that the associations between neighbourhood conditions and youth achievement are the result of neighbourhood factors, or of the differential selection of youth and their families into certain neighbourhoods (Sampson et al, 2002).

The direction of bias resulting from endogenous sorting has been the subject of debate; however, it cannot be determined with any certainty (Dietz, 2002; Duncan and Raudenbush, 1999; Galster, 2008). Often cited as an example that would lead to an overestimation of neighbourhood effects, is the case of parents who devote great effort to the welfare of their children, seeing to it that they reside in a particularly 'good' neighbourhood with access to good schools and peer groups. Part of the apparent statistical association between these children's outcomes and their neighbourhood conditions may, in fact, be the result of the unmeasured parental characteristics that led to the observed neighbourhood characteristics (Evans et al, 1992; Galster et al, 2007). 
A scenario illustrating the underestimation of neighbourhood effects is one in which parents who are "well-equipped to resist the effects of bad neighbourhoods choose to live in them to take advantage of the cheaper housing or perhaps shorter commuting times" (Duncan and Raudenbush, 1999, page 36). Young urban professional parents living in less well-off neighbourhoods because of their proximity to the city center, affordable homes, and perhaps potential for 'revitalisation' may be a case in point. Here, unless parental competence is accounted for in the model, estimated effects of disadvantaged neighbourhood conditions on children's outcomes may be biased downwards.

Although a number of techniques exist to try to overcome endogeneity and selection bias, as several authors have noted, they have important limitations themselves (eg introducing a new type of bias) and have had restricted general applicability thus far (see Dietz, 2002; Galster, 2008; Sampson et al, 2002). Although we could not employ any of these techniques in the current analysis, we plan to apply a differencing approach at a later stage in our research, using measures of students' performance at two different points in time. This should offer protection from selection bias (Galster, 2008); however, because of study retention rates, the sample will be smaller and less representative than the current one.

We would also like to point out that the unmeasured characteristics that would generate endogeneity in our study are those that sort people into neighbourhoods and are associated with youths' school achievement. These are often thought to be parental motivations, ambitions, and skills and behaviour related to children and their upbringing (Evans et al, 1992; Galster et al 2007). Research suggests, however, that some of these parenting characteristics may themselves be affected by the neighbourhood environment. Several qualitative studies have shown that parents adapt their parenting styles and employ different parenting strategies depending on features of their neighbourood context (Furstenberg, 1993; Pinkster and Droogleever Fortuijn, 2008; Valentine, 1997). Such 'adaptable' parenting factors could include how parents seek out and access resources for their children (eg schools, play groups), how they react to social pressures or collective norms in the neighbourhood, and how they monitor or restrict where and with whom their children spend time (Jarrett, 1997; Valentine, 1997). While there is no doubt that nonrandom factors help to sort families into neighbourhoods, it is also likely that, after being sorted, families are still susceptible to effects from their local environment (Oliver et al, 2007). These points do not ease or refute the problem of endogeneity; rather, they highlight the complex interdependencies that are likely to exist between people and their contexts, and the need for more substantive methods and research which account for them (Bronfenbrenner, 1989; Cook et al, 2002; Ellen and Turner, 1997).

Another potential limitation to our study is our operationalisation of youths' neighbourhoods as their addresses in the first year of secondary school. In doing this, we take a static view of youths' residential environments and do not consider residential mobility or neighbourhood change. Other studies have, however, found point-in-time measurements of neighbourhood characteristics to be useful proxies for children's long-run neighbourhood experiences, because the vast majority of families, if they move, move into a similar kind of neighbourhood (Jackson and Mare, 2007; Kunz et al, 2003). We have also relied on readily available official data to describe neighbourhood conditions. These are meant to serve as proxies for the processes that underlie neighbourhood effects (eg collective efficacy and social capital), but which are difficult to measure across neighbourhoods, particularly on a national scale (Sampson et al, 2002). To the extent that these data serve as weak proxies, we may be undercutting or misestimating the role that neighbourhoods play (Brooks-Gunn et al, 1997). 
In conclusion, the results from this study give an indication, for the first time, of the associations between neighbourhood conditions and youth educational achievement in the Netherlands. To better understand these associations, and the mechanisms driving them, more research is needed which considers the relationships between youth, neighbourhoods, schools, and families. As there is evidence that the impact of the neighbourhood is variable, research should examine these relationships across different groups of youth. In particular, a better understanding of the relationships between family/parenting factors and the neighbourhood context, and a stronger link between school and neighbourhood research, seems essential to understanding the influence these contexts may have on youth outcomes. As Kauppinen (2008) explains, neighbourhoods play a large part in selecting students into schools, and it is in schools where some of the contextual effects occur. Research considering the ways parents may mediate or moderate neighbourhood influences on their children also has much to offer (Kohen et al, 2008; Pinderhughes et al, 2001; Pinkster and Droogleever Fortuijn, 2008). An important question for future research is why some students appear to be more or less susceptible to certain neighbourhood effects than others. Whether family or schooling factors play a role in this is an important consideration.

Our results add to the evidence that, even in contexts with relatively strong social welfare and educational policies, neighbourhood effects on youths' school outcomes may be detected. The results suggest that research which measures average neighbourhood effects across all individuals may fail to account for the real extent of effects for certain subgroups. Our study echoes the need for more research on the interconnections between individual and families and the multiple contexts which they inhabit. Combining neighbourhood effects research with school and family effects research is one of the ways we can further our understanding about the roles these contexts play in shaping youths' educational outcomes.

Acknowledgements. We would like to thank the three anonymous reviewers for their helpful comments, as well as Sako Musterd for his comments and suggestions.

\section{References}

Aaronson D, 2000, "A note on the benefits of homeownership" Journal of Urban Economics 47 $356-369$

Ainsworth J W, 2002, "Why does it take a village? The mediation of neighborhood effects on educational achievement" Social Forces 81(1) 117 - 152

Andersson E, 2004, "From valley of sadness to hill of happiness: the significance of surroundings for socioeconomic career" Urban Studies 41641 - 659

Andersson E, Subramanian S, 2006, "Explorations of neighbourhood and educational outcomes for young Swedes" Urban Studies $\mathbf{4 3} 2013$ - 2025

Brännström L, 2008, "Making their mark: the effects of neighbourhood and upper secondary school on educational achievement" European Sociological Review $24463-478$

Bronfenbrenner U, 1989, "Ecological systems theory" Annals of Child Development 6(1) 87-249

Bronfenbrenner U, Morris P A, 1998, "The ecology of developmental processes", in Handbook of Child Psychology volume 1, Eds W Damon, R M Lerner (John Wiley, New York) pp $993-1028$

Brooks-Gunn J, Duncan G, Aber J (Eds), 1997 Neighborhood Poverty: Context and Consequences for Children (Russell Sage Foundation, New York)

Cohen J, 1988 Statistical Power Analysis for the Behavioral Sciences 2nd edition (Erlbaum, Hillsdale, $\mathrm{NJ}$ )

Cook T D, Herman M R, Phillips M, Settersten J, 2002, "Some ways in which neighborhoods, nuclear families, friendship groups, and schools jointly affect changes in early adolescent development" Child Development 73 1283-1309

Crane J, 1991, "The epidemic theory of ghettos and neighborhood effects on dropping out and teenage childbearing" The American Journal of Sociology 96 1226-1259

Crowder K, South S J, 2003, "Neighborhood distress and school dropout: the variable significance of community context" Social Science Research 32 659-698 
Dietz R D, 2002, “The estimation of neighborhood effects in the social sciences: an interdisciplinary approach" Social Science Research 31539 - 575

Dorling D, Smith G, Noble M, Wright G, Burrows R, Bradshaw J, Joshi H, Pattie C, Mitchell R, Green A E, McCulloch A, 2001, "How much does place matter?" Environment and Planning A 33 $1335-1369$

Drukker M, Kaplan C, Feron F, Van Os J, 2003, “Children's health-related quality of life, neighbourhood socio-economic deprivation and social capital: a contextual analysis" Social Science Medicine 57825 - 841

Duncan G J, 1994, "Families and neighbors as sources of disadvantage in the schooling decisions of white and black adolescents" American Journal of Education 103(1) 20-53

Duncan G J, Raudenbush S W, 1999, "Assessing the effects of context in studies of child and youth development" Educational Psychologist $3429-41$

Ellen I G, Turner M A, 1997, "Does neighborhood matter? Assessing recent evidence" Housing Policy Debate $8833-866$

Evans W N, Oates W E, Schwab R M, 1992, "Measuring peer group effects: a study of teenage behavior" Journal of Political Economy 100966 - 991

Furstenberg F F, 1993, "How families manage risk and opportunity in dangerous neighborhoods," in Sociology and the Public Agenda Ed. W J Wilson (Sage, Newbury Park, CA) pp 231-258

Galster G, 2008, "Quantifying the effect of neighbourhood on individuals: challenges, alternative approaches, and promising directions" Schmollers Jahrbuch 128(1) 7-48

Galster G, Marcotte D E, Mandell M, Wolman H, Augustine N, 2007, "The influence of neighborhood poverty during childhood on fertility, education, and earnings outcomes" Housing Studies $22723-751$

Garner C L, Raudenbush S W, 1991, "Neighborhood effects on educational attainment: a multilevel analysis" Sociology of Education 64251 -262

Gramberg P, 1998, "School segregation: the case of Amsterdam" Urban Studies $35547-564$

Gramberg P, 2000 De School als Spiegel van de Omgeving: Een Geografische Kijk op Oderwijs [The school as a mirror of its environment: a geographical view on education], PhD dissertation, Faculty of Social and Behavioural Sciences, University of Amsterdam, Amsterdam

Jackson M I, Mare R D, 2007, "Cross-sectional and longitudinal measurements of neighborhood experience and their effects on children" Social Science Research $36590-610$

Jarrett R L, 1997, "Bringing families back in: neighborhood effects on child development", in Neighborhood Poverty: Context and Consequences for Children Eds J Brooks-Gunn, G Duncan, J Aber (Russell Sage Foundation, New York) pp 48-64

Jencks C, Mayer S E, 1990, "The social consequences of growing up in a poor neighborhood", in Inner City Poverty in the United States Eds L E Lynn, M G H McGreary (National Academy Press, Washington, DC) pp $111-186$

Karsten S, Ledoux G, Roeleveld J, Felix C, Elshof D, 2003, "School choice and ethnic segregation" Educational Policy $17452-477$

Karsten S, Felix C, Ledoux G, Meijnen,W, Roeleveld J, Van Schooten E, 2006, "Choosing segregation or integration? The extent and effects of ethnic segregation in Dutch cities" Education and Urban Society $38228-247$

Kauppinen T M, 2007, "Neighborhood effects in a European city: secondary education of young people in Helsinki" Social Science Research 36421 - 444

Kauppinen T M, 2008, "Schools as mediators of neighbourhood effects on choice between vocational and academic tracks of secondary education in Helsinki" European Sociological Review 24 379-391

Kohen D E, Leventhal T, Dahinten V S, Mcintosh C N, 2008, "Neighborhood disadvantage: pathways of effects for young children" Child Development 79(1) $156-169$

Kunz J, Page M E, Solon G, 2003, "Are point-in-time measures of neighborhood characteristics useful proxies for children's long-run neighborhood environment?" Economics Letters 79 $231-237$

Kuyper H, Lubbers M J,Van der Werf, M P C, 2003, “VOCL'99-1: Technisch rapport” [VOCL'99-1: technical report], Groningen Institute for Educational Research, Groningen

Leventhal T, Brooks-Gunn J, 2000, "The neighborhoods they live in: the effects of neighborhood residence on child and adolescent outcomes" Psychological Bulletin 126309 - 337

Lupton R, 2003, "Neighbourhood effects: can we measure them and does it matter?", CASE paper 73, Centre for Analysis of Social Exclusion, London School of Economics, London 
McCulloch A, 2006, "Variation in children's cognitive and behavioural adjustment between different types of place in the British National Child Development Study" Social Science Medicine $621865-1879$

McCulloch A, Joshi H E, 2001, "Neighbourhood and family influences on the cognitive ability of children in the British National Child Development Study" Social Science Medicine $\mathbf{5 3}$ $579-591$

Oberwittler D, 2007, "The effects of neighbourhood poverty on adolescent problem behaviours: a multi-level analysis differentiated by gender and ethnicity" Housing Studies 22781 - 803

Oliver L N, Dunn J R, Kohen D E, Hertzman C, 2007, "Do neighbourhoods influence the readiness to learn of kindergarten children in Vancouver? A multilevel analysis of neighbourhood effects" Environment and Planning A 39848 - 868

Park R E, Burgess, E W, 1924 Introduction to the Science of Sociology (University of Chicago Press, Chicago, IL)

Pinderhughes E E, Nix R, Foster E M, Jones D, 2001, "Parenting in context: impact of neighborhood poverty, residential stability, public services, social networks, and danger on parental behaviors" Journal of Marriage and Family 63941 - 953

Pinkster F, Droogleever Fortuijn J, 2008, "Watch out for the neighborhood trap! A case study on parental perceptions of and strategies to counter negative neighborhood influences on child development", paper presented at the Association of American Geographers (AAG) Annual General Meeting, 14-19 April, Boston, available from the AAG, 1710 Sixteenth Street NW, Washington, DC

Rankin B H, Quane, J M 2002, "Social contexts and urban adolescent outcomes: the interrelated effects of neighborhoods, families, and peers on African-American youth" Social Problems 49(1) $79-100$

Rasbash J, Steele F, Browne W, Prosser B, 2000 A User's Guide to MLwiN, Version 2.0 Centre for Multilevel Modelling, University of Bristol, Bristol

Raudenbush S W, Bryk A S, 2002 Hierarchical Linear Models: Applications and Data Analysis Methods (Sage, Newbury Park, CA)

Rohe W, Stewart L, 1996, "Home ownership and neighborhood stability" Housing Policy Debate $737-81$

Sampson R J, Morenoff J D, Earls F, 1999, "Beyond social capital: spatial dynamics of collective efficacy for children" American Sociological Review $64633-660$

Sampson R J, Morenoff J D, Gannon-Rowley T, 2002, “Assessing 'neighborhood effects': social processes and new directions in research" Annual Review of Sociology $28443-478$

Sastry N, Ghosh-Dastidar B, Adams J, Pebley A R, 2006, "The design of a multilevel survey of children, families, and communities: the Los Angeles Family and Neighborhood Survey" Social Science Research 351000 - 1024

Shaw C R, McKay H D, 1942 Juvenile Delinquency and Urban Areas (University of Chicago Press, Chicago, IL)

Snijders, T A B, Bosker R J, 1999 Multilevel Analysis: An Introduction to Basic and Advanced Multilevel Modeling (Sage, London)

Teelken C, 1999, "Market mechanisms in education: school choice in The Netherlands, England and Scotland in a comparative perspective" Comparative Education 35283 -302

ten Broeke L, Bosfeld W, van de Kieft M, Gerritsen L, Koopman C, Kuhnen C, Eijken B, 2004, "Schoolkeuzemotieven: onderzoek naar het schoolkeuzeproces van Amsterdamse ouders" [School choice motivation: research about the school choice process of Amsterdam parents], Gemeente Amsterdam, Dienst Onderzoek en statistiek, Amsterdam, http://www.os.amsterdam.nl/pdf/2004_schoolkeuzemotieven.pdf

Valentine G, 1997, “ 'Oh yes I can' 'Oh no you can't': children and parents' understandings of children's competence to negotiate public space safely" Antipode 29 65-89

van Berkel K, 1999, "Steekproef voor schoolloopbaan onderzoek VOCL'99" [Sample for educational career project VOCL'99], Centraal Bureau voor de Statistiek [Statistics Netherlands], Heerlen, The Netherlands

Wilson W J, 1987 The Truly Disadvantaged (University of Chicago Press, Chicago, IL) 
Conditions of use. This article may be downloaded from the E\&P website for personal research by members of subscribing organisations. This PDF may not be placed on any website (or other online distribution system) without permission of the publisher. 